\title{
The development of institutional repositories in East Africa countries: A comparative analysis of Tanzania, Kenya, and Uganda
}

\author{
Joseph Mathew Mwalubanda ${ }^{1}$
}

\begin{abstract}
This paper aims at examining the growth of IR in the East African region (Tanzania, Kenya, and Uganda) from 2010-2020. This study adopted a content analysis methodology. Data for this study was extracted from OpenDOAR (Directory of Open Access Repository), ROAR (Registry of Open Access Repository) and repository websites to identify the language used, subject covered, software used and types of content that are found in East African repositories. The findings of this study reveal that East African region has a total number of 66 repositories, which are registered in OpenDOAR. Kenya is a leading country in the region by having 42 repositories, followed by Tanzania with 14 repositories and Uganda with 10 repositories. The findings show that there is an increase in number of repositories in the region from 4 in 2010 to 66 in 2020. However, the growth is low compared to other parts of the world particularly, Europe, Asia, and America. The study shows the need for librarians, researchers, stakeholders, and East African governments to come together to address the challenges that hinder the growth of repositories in the region. Likewise, mandate policy formulation, training, financial support, OA awareness and technical support are needed in order to overcome those challenges.
\end{abstract}

\section{Keywords}

Institutional Repository, Open Access, Content Growth, Institutional Repository Software, Items Types, Institutional Repository Language, Subject Covered in Repository, East African Region.

\section{Introduction}

With the development of computer and information technology, people changed the way of sharing and exchanging information. This development has, as a result, enhanced the communication media in the scholarly world, and led to the rise and use of institutional repository as a mean of communication by different institutions. Ukwoma and Mole (2017, p.117) define 'Institutional Repository (IR) as an online platform for preservation and disseminating the intellectual output of an institution'. In other words, a combination of different sets of services in providing information regarding theses and dissertations, e-print, and technical report, among others, is another way of describing institutional repository (Ratanya, 2017). As noted by Ratanya (2017, p. 276), 'in the age of electronic publishing and digital content, academic institutions are increasingly realizing the importance of IRs as a vital infrastructure for scholarly communication'. Indeed, this is in line with the United Nations Sustainable Development Goals (UNSDGs) regarding promotion of quality education and supporting innovation in the society.

The task of supporting the institutions in sharing, disseminating, and preserving information that they produce remains the main role of institutional repositories. Furthermore, IRs and Open Access (OA) movement has provided room for different authors and institutions to communicate their findings to the society.

Through the link and OA tools and services (DOAJ, DOAR, ROAR, SHERPA-ROMEO and SPARC) provided to the resources they have, IRs and OA provide the easy way of sharing information between institutions and the communities they serve. As noted by Okpala $(2017$, p.5) 'most universities are now aiming to provide $O A$ to their local contents Vis institutional repositories' and this shows the link between IRs and OA movements to most of the academic institutions. In this regard, most of the 
institutions are striving to achieve UNSDGs by enabling their users to obtain information necessary in their pursuit of education and research. According to Okoroma $(2018$, p.289) universities and other academic institutions all over the world are using IR as a mean of bridging the gap between authors, researchers and other information users. In addition, these serve as the preservation tool of knowledge produced by specific institutions.

Indeed IR has become a good way of sharing information and it assists universities in accomplishing their goals and objectives of serving the community. In this regard, in order for institution to achieve UNSDGs such as quality education, innovation, and infrastructure, use of IR becomes inevitable. Accordingly, as Tapfuma and Hoskins $(2019$, p.1) observe, 'OA journals and IRs are alternative channels for disseminating and communicating research findings'. However, in order to facilitate the use of IRs by organizations and universities, policies are inevitable. These policies will in turn enable these organizations determine the type of information to be hosted by their respective IRs.

\section{Statement of the problem}

The establishment and implementation of IRs has gained momentum globally in recent years. The developed countries have a greater number of institutional repositories compared to the developing countries. This may be observed in different registries of repositories such as the Directory of Open Access Repository (DOAR) and Registry of Open Access Repository (ROAR). Data from those repositories show that most of the African countries are lagging behind in the establishment and implementation of IRs. Dlamini \& Snyman (2017) note that Africa as a continent is struggling in the implementation of IRs both in terms of establishing and use. Different factors such as lack of funds, poor infrastructure, lack of government support and lack of expertise have been attributed to this phenomenon. This study analyzes and compares the characteristics of IRs in East Africa. The study uses openly available web resources to determine the software used in different IRs; type of materials that are hosted in the IRs; type of subject that are covered in the IRs and the growth of the IRs in the East African region.

\section{Objectives}

1. To determine the software used in different IRs.

2. To determine the type of materials that are hosted in the IRs.

3. To determine the type of subjects that are covered in the IRs.

4. To identify the most used languages in East African repositories.

5. To determine the growth of IRs in East Africa region.

\section{Methodology}

Data for this study was collected from the Directory of Open Access Repository (OpenDOAR), Registry of Open Access Repository (ROAR) and repository websites. OpenDOAR and ROAR have been used as the source of data in different studies in the field of repositories and OA (Ezema \& Onyancha, 2017; Verma \& Shulka, 2014; and Gul, Bashir and Ganaie, 2019). Given the importance and usability of OpenDOAR in this study, it is very important to provide some design details and characteristics of its records that are found in the OpenDOAR database. This will allow easy understanding of the information found in the database especially in the growth trend, subject, software, and language used. OpenDOAR which is maintained by the University of Nottingham was developed in collaboration with Lund University under the umbrella of SHERPA services. 
OpenDOAR consists of different records in its database such as:

- Description: this place describes the repository and kind of service that is offered

- Software: shows the type of archived software used by the specific repository when known

- Organization: it shows the origin of the parent organization and it provides official website

- Size: shows the number of records that are hosted in the repository

- Subjects: show the broad description of the subject by following the library of congress classification scheme

- Content types: show the types of materials that are hosted in the repository based on the controlled vocabulary like articles, conferences, etc.

- Languages: show language used in the content types hosted in the repository

- Policies: provide a brief description of the types of policies of the specific repository (like metadata policy, preservation policy, data re-use policy, etc.)

- Remarks: it is a place where additional information is provided about the repository (information like partnership may be found here)

- Repository URL: is the place where users will find the URL address of the specific repository

- OpenDOAR ID: this is the unique number of the registered repository in OpenDOAR database

Therefore, this kind of information is the basis for this study because it provides different characteristics of the repositories. ROAR is maintained by the University of Southampton, UK and is the part of EPrints.org. ROAR data is limited to the number of repositories, software used in archiving materials, types of repositories and the number of records. The core data for this study come from OpenDOAR, and I supplement it with data from ROAR and the repositories websites. The data that was collected from OpenDOAR database is up-to-date and reliable for this study as it has been updated monthly.

OpenDOAR and ROAR have been used to identify different repositories that are found in the East African region (Tanzania, Kenya, and Uganda). As mentioned above, OpenDOAR provides information about the country of originality for every repository. This has assisted the researcher in collecting and scrutinizing data for this study. Moreover, both OpenDOAR and ROAR provide information about registered repositories in the world. Information, like software used, type of IR, number of IR by country, content types, and location of IR are found in those two directories. Data were extracted from OpenDOAR, ROAR and repositories websites and coded in Excel spreadsheet. The study also explores the literature and existing data to know in detail about the growing trend of IR. This exploratory study was completed by using different published literature like books, journal article, and report.

\section{Review of literature}

Growth of IRs in the world

The history of the IRs can be traced from 1990s where many institutions around the world started to implement the use of IR in their libraries. At the global level, there have been notable improvements regarding the number of existing IR from 1991 (Wyk \& Mostert, 2010) to 4,580 (Ogungbeni, Obiamalu, \& Obiora, 2019). Out of 4,580 repositories, Europe has 1,798, North America 1,064, Asia 917, South America 447, Africa 173, Australia 86, Oceania 3, and unknown locations 92. This means that Europe is the leading continent in the world with a large number of repositories. This increase can be attributed to the open access movement in the world where different institutions are trying to assist their societies to have free access to information more easily (Wyk \& Mostert, 2010). As Raju, Adam \& Powell $(2015$, p. 142) observe, 'these repositories quickly evolved into a platform for libraries to publish and showcase institutions entire range of scholarly output including articles, theses,

3/12 Mwalubanda, Joseph Mathew (2021), The development of institutional repositories in East Africa countries: A comparative analysis of Tanzania, Kenya, and Uganda, IASSIST Quarterly 45(3-4), pp. 1-12. DOI: https://doi.org/10.29173/iq1012 
dissertations, and journals'. The promotion of open access movement increases this number of IRs in the world regardless of the challenges that developing countries are facing in implementing it.

\section{Growth of IRs in Africa}

Despite the fact that, Africa is far behind in the establishment and use of IRs as stated in different international registries of repositories such as ROAR, and the OpenDOAR, recent trends indicate substantial increase in IRs in the region. For example, a study conducted by Ogungbeni, Obiamalu, \& Obiora (2019) reveals an increasing number of IRs in Africa from 7 in 2006 to 62 in 2012 and 173 in 2018. This development might have been motivated by the existence of open access movement and free open source software like Dspace, E-print and others.

Despite this promising trend in the continent, the growth rate of IRs in the East African region (Tanzania, Kenya, and Uganda) is still very low. Kenya is the leading country in East Africa with 42 IRs, followed by Tanzania with 14 and Uganda with 10 IRs (OpenDOAR, 2020). Kakai, Masoke, \& OkelloObura (2018) point to challenges like lack of awareness, poor infrastructure, culture, technology skills, lack of support from institutions and government, and lack of funds as factors that make most countries in East Africa to be behind compared to other places like Europe and America.

\section{Content-type of materials in IRs}

Empirical evidence shows that most of IRs content types are journal articles (Abrizah, Noorhidawati \& Kiram 2010; Ezema \& Onyacha, 2017; Shijitha \& Majeed, 2018; Dhanavandan \& Tamizhchelvan 2014). Apart from journal articles, some of the IRs particularly in developing countries were found to host dissertations and theses (Ejikeme \& Ezema 2019; Verma \& Shulka 2014). This can be due to the primary functions of IRs which is to support parent organization activities.

\section{Subject covered by IRs}

The choice of which subjects are to be included in IRs depends on many factors including the nature of the institution and the audience intended. Most of the IRs are owned by academic institutions and therefore they support the work of parent organizations in preserving and disseminating research and other publications which are produced in those institutions. Studies suggest that most of IRs are of multidisciplinary in nature (Ezema \& Onyacha, 2017; Shajitha \& Majeed, 2018). In this case, the nature of the content includes a number of subjects.

\section{Software used by IRs}

In making sure that content management is effective, different IRs have the option of selecting a proper software to use. That software can be open source, built-in or proprietary in nature but they serve the same purpose of managing the content of IRs. Evidence from different studies identified Dspace, GNU Eprints and OPUS as the common software used in conent management (Shajitha \& Majeed 2018; Mezbah-ul-Islam 2014; Ogungbeni, Obiamalu, \& Obiora 2019; Ezema \& Onyacha, 2017; Tapfuma \& Hoskins 2019; Sharma, Meichieo, \& Saha 2008; Oguche 2018; and Sahu \& Parabhoi 2019).

The existence of different content management software, requires each institution intending to implement and manage IRs to conduct intensive research to determine type of software to be used for their repositories. Literature suggests that different conditions and criteria may be considered when selecting appropriate software for use. This includes the 'needs of the user, functionality of the software, technical specifications, repository and system administration, content management, dissemination, archiving and system maintenance' (Smith, 2015, p.9).

4/12 Mwalubanda, Joseph Mathew (2021), The development of institutional repositories in East Africa countries: A comparative analysis of Tanzania, Kenya, and Uganda, IASSIST Quarterly 45(3-4), pp. 1-12. DOI: https://doi.org/10.29173/iq1012 


\section{Language}

One of the important elements in IRs is the language to be used target audience. Yet, the language to be used in IRs varies according to the nature of intended audience and the language they use. However, the most dominant languages used in a good number of IRs include English, followed by French and German (Ibrahim \& Beigh 201; Ezema \& Onyancha, 2017). Other languages are used depending on the area where IR is located and the functions that it serves to the society. In this case, apart from English, French and German as common languages, Hindi, Sanskrit, Arabic, Dyuthi, Malayalam, Kannada, Bangla, Marathi, Bengali, Tamil, Gujarati, Sanskrit, Sinhalese and Pashto were found to be used though at a minimal rate (Gul, Bashir \& Ganaie 2020; Shajitha \& Majeed 2018).

Policy

It is the task of any IRs to provide guideline on how information will be deposited and presented. Further such guidelines should also specify individuals who have rights to deposit in the IRs. Apart from preservation and presentation, these guidelines should also address specific areas like, meta data, data re-use, content policy and submission policy. As elaborated by Nunda \& Elia (2019, p.3), 'a clear institutional repository policy and managerial issues are crucial in the operability and sustainability of institutional repositories as they guide on the type of content deposited, preserved, withdrawn and the day-to-day interoperability of institutional repositories'.

The importance of IR policy cannot be underestimated as it acts as a proven guidelines which assist members of the community to have easy access and use of IRs without violating key issues like copy rights. Despite the importance and relevance of IR policies, recent studies by Gul, Bashir \& Ganaie (2020); Sahu \& Parabhoi (2019) conducted in Asia and German, Switzerland and Austria respectively, revealed that most of the IRs do not have policies for metadata re-use, data re-use policy, content policy, submission policy, and preservation policy, while small number of IRs have one among the mentioned policies. Although there are no clearly stipulated reasons for the absence of IR policies in the mentioned countries, the reasons might be associated with what was presented by Xia et al 2012 and Lynch 2003, who showed the little contribution of the said IR guiding policies. To them IR policies have been the reason for the failure of IRs in many institutions as some of the policies are trying to force people to use IRs.

In order to ensure effectiveness and usefulness of the IRs policy, there is a need for considering different stakeholders when institutions are deciding to impose policy in the implementation of IRs. This will enable the institutions to come up with relevant and reliable policy which serves the institutions, authors and community at large that are likely to use IRs as the platform for sharing scholarly communication. One of the important elements to be stated in the policy should be on the role of different actors working on the implementation of IRs. Likewise, there has to be collaboration and coordination between different sections and fields so that institutions will achieve the planned goals for the establishment of IRs (Smith, 2015).

\section{Discussion \& Findings}

\section{Number of IR in East African Countries}

The findings reveal that Kenya is the leading country in East Africa and has 42 (61\%) repositories, followed by Tanzania 14 (21\%), and Uganda which has only $10(15 \%)$. This correlates with the good economy (GDP per capita) that Kenya has compared to Tanzania and Uganda. Furthermore, OA policy formulation, and collaboration with different organizations such as Kenya Library and Information Services Consortium and Electronic Information for Libraries with libraries in Kenya assisted much in the establishment of IRs in most universities in Kenya (Chilimo, 2015). The total number of IRs in all three countries which have been registered in OpenDOAR up to 18 May 2020 was 66.

5/12 Mwalubanda, Joseph Mathew (2021), The development of institutional repositories in East Africa countries: A comparative analysis of Tanzania, Kenya, and Uganda, IASSIST Quarterly 45(3-4), pp. 1-12. DOI: https://doi.org/10.29173/iq1012 
Table 1: Number of IRs in East African countries

\begin{tabular}{|c|l|c|c|}
\hline SN & \multicolumn{1}{|c|}{ Countries } & Number of IR & Percentage \% \\
\hline 1. & Tanzania & 14 & $21 \%$ \\
\hline 2. & Kenya & 42 & $61 \%$ \\
\hline 3. & Uganda & 10 & $15 \%$ \\
\hline \multicolumn{2}{|c|}{ Total } & 66 & $100 \%$ \\
\hline
\end{tabular}

Source: Directory of Open Access Repository (18-May-2020)

Types of IR

The findings reveal that a total of 63 (95\%) IRs were established by universities, research-based institutions and higher learning institutions, while government IRs were $2(3 \%)$, and disciplinary IRs was 1 (2\%). These findings seem to correlate with what was noted by Ezema \& Onyancha (2017, p.110): that 'the major challenge of African governments is lack of interest in education and research'. This is demonstrated by the number of government repositories presented in OpenDOAR. The majority of IRs are institutionally based because of the research activities and the need for promoting scholarly communications in society. This is confirmed to the previous studies of (Verma \& Shulka, 2014; Ibrahim \& Beigh, 2019; Ezema \& Onyancha, 2017; Sahu \& Parabhoi, 2019 and Singh, 2014) that IRs leads as the type of repository in most places.

Table 2: Types of IRs in East African countries

\begin{tabular}{|c|l|l|c|c|}
\hline S/N & Type of IR & Number & Percentage (\%) \\
\cline { 2 - 5 } 1. & Disciplinary & 1 & $2 \%$ \\
\hline 2. & Government & 2 & $3 \%$ \\
\hline 3. & Institutional & 63 & $95 \%$ \\
\hline \multicolumn{2}{|c|}{ Total } & 66 & $100 \%$ \\
\hline
\end{tabular}

Source: Directory of Open Access Repository (18-May-2020)

\section{Software used in IRs}

In implementing and developing an IR, institutions may opt to use either open source or proprietary software. There are several different types of software available for use into IRs. The study established that most of the institutions opt to use Dspace 60 (91\%), followed by EPrints $3(4.5 \%)$, Drupal $1(1.5 \%)$, and Greenstone 1 (1.5\%). However, $1(1.5 \%)$ repository did not specify the type of software used. The findings show that Dspace is the leading software for most of the repositories. The use of Dspace can be attributed to the fact that it is free open-source software, it is cheap to install and to maintain, and it has user-friendly features. The same findings have been revealed by Ezema \& Onyancha (2017), Ejikeme \& Ezema (2019), Singh (2014), Verma \& Shukla (2014), and Oguche (2018). However, this is different from other studies such as those done by Ibrahim \& Beigh (2019) and Sahu \& Parabhoi (2019) where the preferred software was OPUS and Eprints. Therefore, the use Dspace software by most of East African IRs may have been influenced by the fact that it is open access software and it easy to use and install.

6/12 Mwalubanda, Joseph Mathew (2021), The development of institutional repositories in East Africa countries: A comparative analysis of Tanzania, Kenya, and Uganda, IASSIST Quarterly 45(3-4), pp. 1-12. DOI: https://doi.org/10.29173/iq1012 
Table 3: Software used in East African countries IRs

\begin{tabular}{|c|l|c|c|}
\hline S/N & Software & Number & Percentage (\%) \\
\hline 1. & Dspace & 60 & $91 \%$ \\
\hline 2. & Eprints & 3 & $4.5 \%$ \\
\hline 3. & Drupal & 1 & $1.5 \%$ \\
\hline 4. & Greenstone & 1 & $1.5 \%$ \\
\hline 5. & Unknown & 1 & $1.5 \%$ \\
\hline \multicolumn{2}{|c|}{ Total } & 66 & $100 \%$ \\
\hline
\end{tabular}

Source: Directory of Open Access repository (18-May-2020)

\section{Language used}

In East African region (Tanzania, Kenya and Uganda) the commonly used official language are Kiswahili and English. The findings reveal that English is the dominant language in East Africa as 66 (100\%) repositories host materials in English. However, the study also found that 3 repositories had materials in Kiswahili while 2 repositories had materials in French. Publications in local languages were few with all language such as Swahili which is dominant language used in the East African community.

The publication of electronic resources in English in all the repositories can be attributed to the fact that English used as a medium of instruction in education systems and as the official language in the region. Furthermore, the need to disseminate information globally has also influenced the use of English by most of these IRs. As Ezema and Onyacha (2017, p.107), observe 'in scholarly communication, language of research publication is critical to international scientific publication'. For this reason, it is important to use the language that is understood by many people in order to facilitate easy access of research works. This is consistent with previous studies which had also confirmed that English is the dominant language used in most repositories (Ezema \& Onyancha, 2017; Sahu \& Parabhoi, 2014; Ibrahim\& Beigh, 2019; Verma \& Sulka, 2014 and Shajitha \& Majeed, 2018).

Table 4: Language used in IRs

\begin{tabular}{|l|l|c|}
\hline S/N & Languages & Number of IR \\
\hline 1. & Swahili & 3 \\
\hline 2. & English & 66 \\
\hline 3. & French & 2 \\
\hline
\end{tabular}

Source: Directory of Open Access Repository (18-May-2020)

\section{Policies}

Table 5 indicates the policies of IRs on these three countries. The policy documents have included metadata policy, data policy, preservation policy, content policy, and submission policy. The findings show that $42(63.6 \%)$ repositories do not have written policies and $24(36.4 \%)$ had their policies. The majority of IRs did not define policies for their repositories. Sahu \& Parabhoi (2019) reveal the same findings about a comparative study of German, Switzerland, and Austria on the OA Repository. Thus,

7/12 Mwalubanda, Joseph Mathew (2021), The development of institutional repositories in East Africa countries: A comparative analysis of Tanzania, Kenya, and Uganda, IASSIST Quarterly 45(3-4), pp. 1-12. DOI: https://doi.org/10.29173/iq1012 
most of the repositories experience difficulties for lack of guidance in those areas. This can be the challenge of many IRs in the world because having policy documents needs involvement of many stakeholders and support from parent organizations in order to contribute to the sustainable maintenance and management of the IR.

Table 5: Policies in IRs

\begin{tabular}{|l|l|c|r|}
\hline S/N & Policies & No. of repositories & Percentage \\
\hline 1. & Yes & 24 & $36.4 \%$ \\
\hline 2. & No & 42 & $63.6 \%$ \\
\hline & Total & 66 & $100 \%$ \\
\hline
\end{tabular}

Source: Directory of Open Access Repository (18-May-2020)

\section{Content types}

The study established that institutional repositories in the East African countries had the following type of content, namely, journal articles 57 (86\%), theses and dissertations 54 (82\%), conference and workshop papers $43(65 \%)$, reports and working papers 37 (56\%), books, chapters and sections 28 (42\%), learning objects 19 (29\%), bibliographic references $16(24 \%)$, other special item types 19 (29\%) and datasets $1(2 \%)$. Journal articles are the leading content type on most repositories in the East African countries. Most of these repositories are hosted by research institution and universities as they publish journal articles to support activities of their parent institutions. Previous studies also confirm journal articles as the dominant content type in most of the repositories (Ibrahim \& Beigh, 2019; Ezema \& Onyancha, 2017; Shajitha \& Majeed, 2018; Verma \& Shulka, 2014; Singh, 2014; and Ejikeme and Ezema, 2019).

Table 6: Content types of East African countries IRs

\begin{tabular}{|l|l|c|l|}
\hline S/N & Content type & No. of repositories & Percentage \\
\hline 1. & Journal Article & 57 & $86 \%$ \\
\hline 2. & Conferences and Workshop Papers & 43 & $65 \%$ \\
\hline 3. & Theses and Dissertation & 54 & $82 \%$ \\
\hline 4. & Reports and Working Papers & 37 & $56 \%$ \\
\hline 5. & Books, Chapters and Sections & 28 & $42 \%$ \\
\hline 6. & Learning Objects & 19 & $29 \%$ \\
\hline 7. & Other Special Items & 19 & $29 \%$ \\
\hline 8. & Bibliographic References & 16 & $24 \%$ \\
\hline 9. & Datasets & 1 & $2 \%$ \\
\hline
\end{tabular}

Source: Directory of Open Access repository (18-May-2020)

8/12 Mwalubanda, Joseph Mathew (2021), The development of institutional repositories in East Africa countries: A comparative analysis of Tanzania, Kenya, and Uganda, IASSIST Quarterly 45(3-4), pp. 1-12. DOI: https://doi.org/10.29173/iq1012 


\section{Subjects covered in IR}

Subject coverage in OpenDOAR has been arranged using broad subject description of the library of congress classification scheme. Thus, other repositories with wide range of subject have been registered as multidisciplinary repositories and others have been registered based on the subjects that they cover. The findings show that majority of subjects in IRs were multidisciplinary in nature and followed by other subjects as shown in figure (6) below. This can be attributed to the fact that most of the repositories are institutions by nature and that is the way they register their institutions in OpenDOAR. These findings are consistent with previous studies on this subject (Ibrahim \& Beigh, 2019; Ezema \& Onyancha, 2017; Singh, 2014; Verma \& Shulka, 2014; Shajitha \& Majeed, 2018, and Abrizah, Noorhidawati and Kiran, 2017). Again, the multidisciplinary nature of these IRs may also be linked to the fact that these repositories are IRs by nature and thus they are designed to support universities as they offer services to their communities in different areas of specialization.

\section{Figure 1: Subject coverage in East African countries repositories}

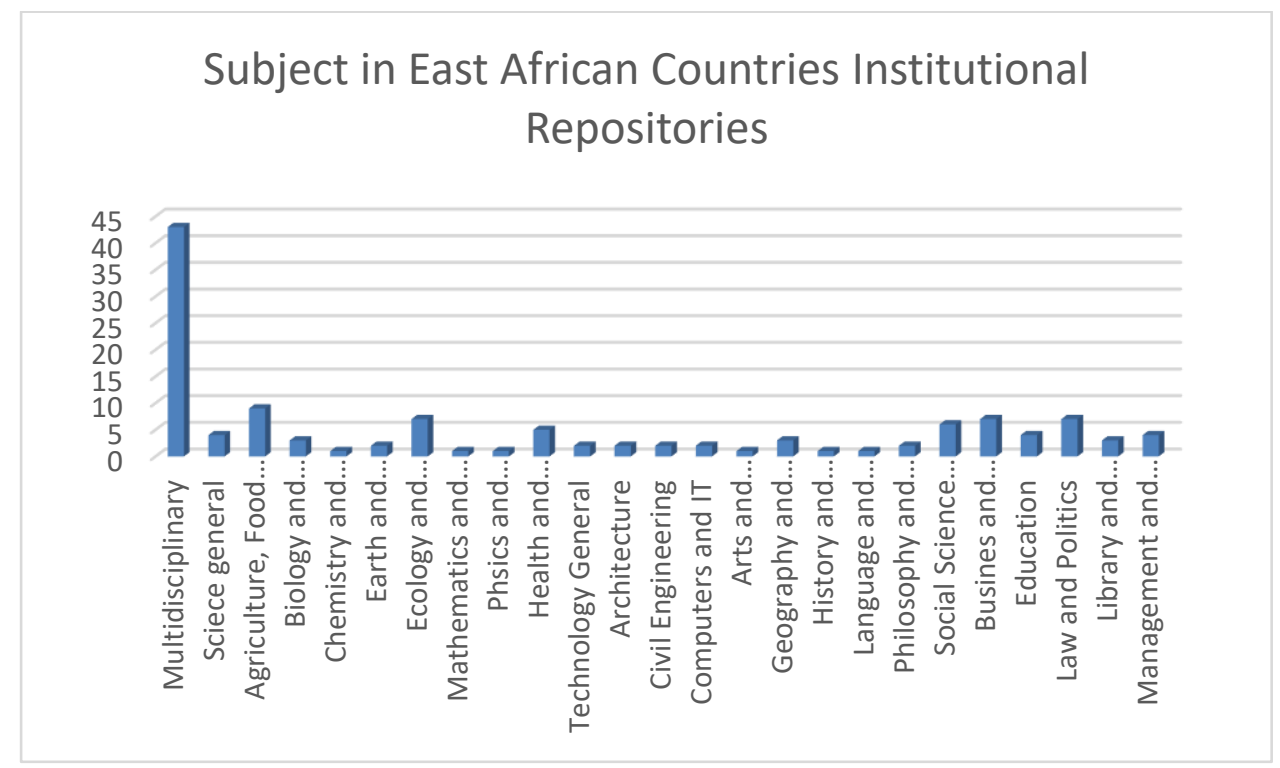

Source: Directory of Open Access Repository (18-May-2020)

\section{Growth of IRs in East African Countries}

The findings for the growth of IRs in East African countries from 2010 to 2020 show that in 2013, 2015, and 2019, there was a rise of many IRs in the region. The first IR in East Africa was established in 2007 by Makerere University in Uganda followed by other universities from Kenya and Tanzania in 2008 and 2009. In 2010 most of the Universities in Kenya, Uganda and Tanzania had started the process of establishing the IRs in their institutions. However, for Tanzania and Uganda, the growth of IRs is low compared to Kenya, and there is no registration of new IR in the OpenDOAR and ROAR for 2011, 2014, 2016, 2017 and 2020. In Kenya, the growth of IR registration and establishment is high compared to Tanzania and Uganda because every year from 2010 to 2020 there was new registration in OpenDOAR and ROAR. The total number of repositories in these three countries was 66 by 18-May-2020. These data were collected from the OpenDOAR and ROAR. This represents a positive development when compared with 2017 data in which only 35 repositories existed in the region.

9/12 Mwalubanda, Joseph Mathew (2021), The development of institutional repositories in East Africa countries: A comparative analysis of Tanzania, Kenya, and Uganda, IASSIST Quarterly 45(3-4), pp. 1-12. DOI: https://doi.org/10.29173/iq1012 
Figure 2: The growth trend of repositories in East African countries

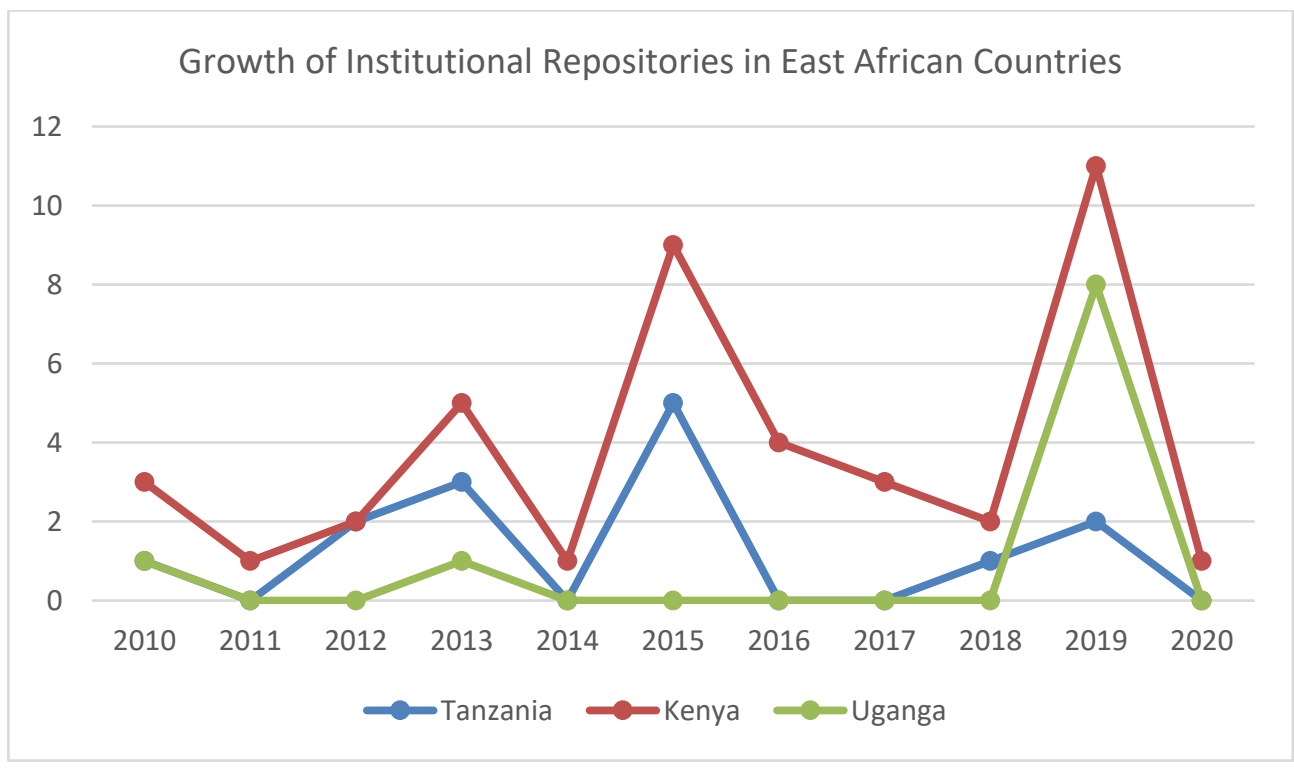

Source: Open Directory of Open Access Repository (18-May-2020)

\section{Conclusion}

The study will assist stakeholders in the East African region (Tanzania, Kenya and Uganda) to see their initiatives on supporting the development of IR in region. However, more support from stakeholders is needed in providing training to librarians, good IT infrastructure, collaboration between library organizations and stakeholders. Government support is also needed in making sure the sector is having good development because good IR environment is critical for these countries to achieve UNSDGs especially innovation, research and providing quality education.

Again, more work still needs to be done in order to understand the driving forces behind the growth of repositories, and the reasons that influence the development of such repositories. Due to methodological approach this study could only speculate the reason why most of the materials are not in local languages like Kiswahili and how the content of repositories grows from time to time in the region. Therefore, this kind of study was based on growth numbers of IRs in the region. Future studies should therefore investigate the content growth and general development of repositories in East African region. There is need to identify the content of repositories which is growing and the underlying motivation instead of just looking at the bare numbers of material and repositories. Furthermore, the use of local languages in materials hosted in the repositories in the East African region should be examined to identify the various languages in use. However, future studies should adopt a methodology, such as the use of interviews and questionnaires in order to give the researcher in-depth information about the study.

10/12 Mwalubanda, Joseph Mathew (2021), The development of institutional repositories in East Africa countries: A comparative analysis of Tanzania, Kenya, and Uganda, IASSIST Quarterly 45(3-4), pp. 1-12. DOI: https://doi.org/10.29173/iq1012 


\section{References}

Abrizah, A, Noorhidawati, A, \& Kiran, K 2010, 'Global Visibility of Asian universities Open Access institutional repositories', Malaysian Journal of Library \& Information Science, vol.15, no.3, pp.53-73.

Chilimo, W 2015, 'Green open access in Kenya: a review of the content, policies, and usage of Institutional repositories', https://www.researchgate.net/publication/327187267.

Dhanavandan, S, \& Tamizhchelvan, M 2014, 'Institutional Repositories in South Asian Countries: A Study on Trends and Development', Brazilian Journal of Information Science: Research Trends, vol.8, no.1/2.

Dlamini, NN, \& Snyman, M 2017, 'Institutional repositories in Africa: obstacles and challenges', Library Review, vol.66, no.6-7, pp.535-548, Doi: https://doi.org/10.1108/LR-03-2017-0021.

Ejikeme, AN, \& Ezema, IJ 2019,' The Potentials of Open Access Initiatives and the Development of Institutional Repositories in Nigeria: Implications for Scholarly Communication', Publishing Research Quarterly vol.35, no.1, pp.1-16.

Ezema, IJ, \& Onyancha, OB 2017,' Open access publishing in Africa: Advancing research outputs to global visibility', African Journal of Library, Archives \& Information Science, vol.27, no.2,pp. 97115, https://www.ajol.info/index.php/ajlais/article/view/164661.

Gul, S, Bashir, S, \& Shabir, AG 2019,'Evaluation of institutional repositories of south Asia', Online Information Review, vol.43 no.1, pp.192-212. Doi: https://doi.org/10.1108/OIR-03-2019-0087

Ibrahim, S, \& Beigh, IN 2019,'Contribution of UK open access repositories to OpenDOAR', Library

Philosophy and Practice, pp.1-10, https://digitalcommons.unl.edu/libphilprac/2592/

Kakai, M, Musoke, MGN, \& Okello-Obura, C 2018, 'Open access institutional repositories in universities in East Africa', Information and Learning Science, vol.119, no.11, pp.667-681, Doi: https://doi.org/10.1108/ILS-07-2018-0066

Lynch, CA 2003, 'Institutional Repositories: Essential Infrastructure for Scholarship in the Digital Age', Portal: Libraries and Academy, vol.3, no.2, pp327-336, Doi. https://doi.org/10.1353/pla.2003.0039.

Nunda, IM, \& Elia, EF 2019, 'Institutional repositories adoption and use in selected Tanzania higher learning institutions'.

Oguche, D 2018, 'The state of institutional repositories and scholarly communication in Nigeria',

Global Knowledge, Memory and Communication, vol.67, no.1/2, pp.19-33. Doi: https://doi.org/10.1108/GKMC-04-2017-0033.

Okoroma, FN 2018, 'Awareness, knowledge, and attitude of lectures towards institutional repositories in university libraries in Nigeria', Digital library perspectives, vol.34, no.4, pp.288307. Doi: https://doi.org/10.1108/DLP-04-2018-0011.

Ogungbeni, JI, Obiamalu, AR, \& Obiora, KU 2019, 'Open Digital Repositories: Prospects of African Countries within the global information space', Library Philosophy and Practice (e-journal). https://digitalcommons.unl.edu/libphilprac/2444.

Okpala, H.H 2017 'Access Tools and Services to Open Access: DOAR, ROAR, SHERPA-ROMEO, SPARC and DOAJ', Informatics Studies, vol.4, no.3, pp. 05-20.OpenDOAR, 2020, 'The Directory of Open Access Repositories', https://v2.sherpa.ac.uk/opendoar/search.html.

Pinfield, S, Salter, J, Bath, PA., Hubbard, B, Millington, P, Anders, JH, et al. 2014, 'Open Access repositories worldwide, 2005-2012: Past growth, current characteristics, and future possibilities', Journal of Association for Information Science and Technology, vol.65, no.12, pp.2404-2421. Doi: https://doi.org/10.1002/asi.23131.

Rahman, MM, \& Mezbah-ul-Islam, M 2014, 'Issues and strategy of institutional repositories (IR) in Bangladesh: a paradigm shift', The electronic Library, vol.32, no.1, pp.47-61. Doi: https://doi.org/10.1108/EL-02-2012-0020.

11/12 Mwalubanda, Joseph Mathew (2021), The development of institutional repositories in East Africa countries: A comparative analysis of Tanzania, Kenya, and Uganda, IASSIST Quarterly 45(3-4), pp. 1-12. DOI: https://doi.org/10.29173/iq1012 
Raju, R, Adam, A, \& Powell, C 2015, 'Promoting open scholarship in Africa: Benefits and best library Practices', Library Trends, vol.64, no.1, pp.136-160.

https://www.semanticscholar.org/paper/Promoting-Open-Scholarship-in-Africa\%3A-Benefitsand-Raju-Adam/99af69dbae19a5b69bc654148e58d9ad0d549ec4

Registry of Open Access Repository, http://roar.eprints.org.

Registry of Open Access Repository Mandates and Policies, https://roarmap.eprints.org.

Rutanya, FC 2017, 'Institutional Repository: access and use by academic staff at Egerton University Kenya', Library Management Journal, vol.38, no.4-5, pp.276-284.

Sahu, RR, \& Parabhoi, L 2019, 'Open access repository: A comparative study of Germany,

Switzerland and Austria', Library Philosophy and Practice, pp.1-9, https://digitalcommons.unl.edu/libphilprac/2511/

Shajitha, C, \& KC, AM 2018), 'Content growth of institutional repositories in South India: A status Report', Global Knowledge, Memory and Communication, vol.67, no.8, pp.547-565. Doi: https://doi.org/10.1108/GKMC-02-2018-0018

Sharma, AJ, Meichieo, K, \& Saha, NC 2008, 'Institutional Repositories and Skills Requirements, a New Horizon to Preserve the Intellectual Output: An Indian Perspective', Planner, pp.336-353.

Smith, Ina 2015, 'Open Access Infrastructure: Open Access for library schools', UNESCO publications.

Tapfuma, MM, \& Hoskins, RG 2019, 'Usage of Institutional Repositories in Zimbabwe's Public Universities', South Africa Journal of Information Management, vol.21, no.1, pp.1-9. Doi: https://doi.org/10.4102/sajim.v21i1.1039.

Ukwoma, SC, \& Mole, AJC 2017, 'Utilization of Institutional Repositories for Searching Information Sources, Self- Archiving and Preservation of Research Publication in Selected Nigeria Universities', Afr. J. Arch \& Info. Sc, vol.27, no. 2, pp.117-130.

Verma, NK, \& Shulka, A 2014, 'Evaluating Growth and Development of Open Access Repositories: A Case Study of OpenDOAR', International conference on Knowledge Organization in Academic Libraries, pp.59-67, Jaipur.

Wyk, B, \& Mostert, J 2010, 'Towards Enhanced Access to Africa's Research and Local Content: A Case Study of the Institutional Depository Project, University of Zululand, South Africa', Afr.J. Lib \& Sc, vol.21, no.2, pp.139-151.

Xia, J, Gilchrist, SB, Smith, NXP, Kingery, JA, Radecki, JR, Wilhelm, ML et al. 2012, 'A review of open access self-archiving mandate policies', Portal: Libraries and the Academy, vol.12, no.1, pp.85102. Doi: http://dx.doi.org/10.1353/pla.2012.0000

\section{Endnotes}

1 Joseph Mathew Mwalubanda is a Librarian and researcher at the Department of Library, Tanzania Institute of Accountancy and can be reached by joseph.mwalubanda@tia.ac.tz or mwalubandajoseph88@gmail.com

12/12 Mwalubanda, Joseph Mathew (2021), The development of institutional repositories in East Africa countries: A comparative analysis of Tanzania, Kenya, and Uganda, IASSIST Quarterly 45(3-4), pp. 1-12. DOI: https://doi.org/10.29173/iq1012 